\title{
Prediction of Flux Core Arc Welding (FCAW) Bead Geometry and Welding Parameters for 1G Position
}

\author{
M. F. Abdul Razak, Abdul Ghalib, Abdullah, and M. A. H. Ramli
}

\begin{abstract}
Flux Core Arc Welding (FCAW)is a popular choice for metal fabrication. Correct welding parameter and bead geometry are required before a robot can perform quality welding. An experiment was conducted to study the correlation between weld bead geometry and welding parameter for bead-on-plate in $1 \mathrm{G}$ position, and subsequently to develop a tool that can support the input requirement of the robot without resorting to unproductive trial and error. Coupons of quality weld deposit were produced experimentally by FCAW process and the bead geometry is measured and tabulated. The correlation of Heat Input and weld bead geometry is best represented by their trend-line equations. Incorporating these equations into a calculator format, the weld bead geometry and welding parameters can be predicted to produce a wide range of bead geometry. The deviation between predicted data and experimental measurement on actual welding is less than $1 \mathrm{~mm}$, while the Mean Absolute Deviation is less than $0.6 \mathrm{~mm}$.
\end{abstract}

Index Terms-Prediction of bead geometry, prediction of welding parameter, FCAW welding.

\section{INTRODUCTION}

Flux core arc welding (FCAW) process is popular choice for fabrication of metal components [1]. The process is semi-automatic, consumable electrode is automatically issued from the hand-hold welding torch. The flux in the core of consumable wire can generated shielding gas to protect the weld pool, but external CO2 gases shielding will produce better weld quality [2], [3]. The most critical factors that determine the success of welding are the correct choice of welding parameter and the skill of welder to manipulate the welding torch. Based on the requirement of a code of practice, the quality of welding is considered acceptable when the deposit has adequate penetration, right bead profile, absence of external and internal defects [4], [5]. Visual and several testing methods can be applied to inspect and evaluate the quality of welding. In Japan, the applications of FCAW have exceeded the combined usage of all other arc welding processes. It is popular even among the small scale supporting industries. FCAW has the advantage of high deposition like SAW and GMAW plus the versatility of shielded metal arc welding (SMAW). It is believed that in the next decade its usage would be a worldwide trend. The market for the machine, consumable and product of FCAW will be expected increased by many folds [6], [7].

Manuscript received July 6, 2015; revised October 30, 2015

M. F. Abdul Razak and M. A. H Ramli are with the Malaysia Institute of Marine Technology, Universiti Kuala Lumpur, 32200, Lumut, Malaysia (e-mail: mfaizalar@unikl.edu.my,mohdamin@unikl.edu.my).

Abdul Ghalib is with Universiti Teknology Mara (UiTM), Faculty of Mechanical Engineering, 40450 Selangor, Malaysia (e-mail: ghalibtham@yahoo.com).
The human skill can be replaced by mechanized welding system like orbital welding system and welding robot [8], [9], [10]. The productivity of mechanized system is excellent; output quality is consistent and requires only minimal supervision. However all mechanized welding systems demand the input of correct welding parameter before welding can start. Selection of welding parameter by trial and error approach is costly and unproductive. Research on the development of tools to predict the weld bead geometry and welding parameters had been carried out in the past. $\mathrm{H}$. H. Na [11] had optimized the welding parameter by using Taguchi Method. Mukhopadhyay [12] had predicted bead geometry of GMAW process by using curve fitting techniques and graphical models. Artificial Neural Networks (ANN) and Particle Swarm Optimization (PSO) Algorithm were applied by D. Katherasan [13]. Derivation of mathematical modeling from these researchers showed that the bead geometry can be predicted if statistical analysis tools are available to process them, but to date. The output is limited and not adequate for industrial application. Tham [14] and Hamidin [15] had applied the Heat input-Bead geometry correlation to develop the tool to predict quality GMAW and SAW fillet bead geometry for all welding positions. Based on this methodology, the prediction calculator for FCAW in flat position (1G) will be developed.

The deposition bead geometry is correlated to the arc behavior and arc characteristic. Wide arc gives wide bead profile; narrow arc gives narrow bead profile. The physics of the welding arc can be interpreted to represent the deposition bead geometry. The arc behavior also changes with variation in heat input, which also influenced the quality and characteristic of weld deposition. Thus the knowledge of correlation between arc behavior, heat input and deposition bead geometry will support the formulation and development of accurate prediction tool.

Welding Heat Input, $\left(\mathrm{Q}=\frac{I E}{v}\right.$, $\mathrm{I}$ is the welding current in amp, $E$ is voltage in volt and $v$ is welding speed in $\mathrm{mm} / \mathrm{s}$.) plays a significant influence on weld bead geometry for all types of weld deposition. It has effect on the quality of fusion, the integrity and strength of weldment [9].

The Mean Absolute Deviation is also known as Mean Deviation. It is the mean of the absolute deviations of a set of data from another reference data (such as experimental data). It is simply defined as a measure of dispersion, a measure of how many the differences between the actual data from another set of data with higher degree of reliability. This MAD can be defined by the formula for better understanding as follows:

$$
\operatorname{MAD}=\frac{1}{n} \sum_{i=1}^{n}\left(X_{i}-\bar{X}\right)
$$


where $n$ is the number of observed values or sample size, $x_{i}$ represent the individual values and $x$-bar represents observed values. This forecast accuracy method is closely similar to the Mean Squared Error (MSE) but the MAD is commonly used because it does not require squaring.

The application welding of codes and standards normally comply with these standards such as US, UK and ISO standards. These requirements standard is a benchmark for welding quality. In Malaysian industry, many pressurize products are fabricated by following the American standards which are AWS, API and ASME as their references. Few companies utilize the British Standard and ISO EN (European) Standard ISO 5817 and ISO 10042.

\section{EXPERIMENTAL AND PROCEDURE}

\section{A. Material and Welding Procedure}

The mild steel bar of size $300 \mathrm{~mm}$ length $\times 25 \mathrm{~mm}$ width $\times$ $9 \mathrm{~mm}$ thick was used as the base metal. FCAW bead-on-plate welding was performed by OTC Almega A11-B4 welding robot, shielded by $100 \%$ CO2. The consumable wire was 1.2 mm diameter (AWS classification E71T-1), the torch angle is inclined at $15 \mathrm{deg}$, and wire extension was $15 \mathrm{~mm}$. Welding current ranged between $100 \mathrm{~A}$ to $350 \mathrm{~A}$, voltage between $18 \mathrm{~V}$ to $35 \mathrm{~V}$ and travel speed between $2 \mathrm{~mm} / \mathrm{s}$ to $15 \mathrm{~mm} / \mathrm{s}$. The weld on each bar was deposited with constant current and voltage, but at six welding speed.

\section{B. Metallography}

The weld depositions were inspected, evaluated and only good quality bead were selected for macro etching test. The specimens were cut in traverse direction by using cut-of machine, polished to mirror-finish, etched by 5\% Nital reagent to reveal the macro-section view. The weld bead geometry was then be measured by a vernier caliper.

\section{THE ANALYSIS PROCEDURE}

The weld bead geometry (Bead width, Bead height, Throat size and Penetration) were plotted with heat input. The trend-line graphs for each geometry were generated, and then the trend-line equationswere applied to predict the geometry of every experimental welded sample. The deviations or errors of the predicted geometry were calculated. Whenever error was more than $1 \mathrm{~mm}$, the welded sample was re-inspected, possibly the welded sample had poor profile quality or perhaps error in measurement or grouping of sample. If the cause was due to poor quality deposition, it was removed from the list of data, if the error was due to measurement or grouping of weld sample, the data record was rearranged. About $4 \%$ of the samples had deviation error more than $1 \mathrm{~mm}$. Reapply the improved trend-line equation to predict weld bead geometry until the deviation is satisfactory and the Mean Absolute Deviation (MAD) be at the lowest possible. The bead geometry with respect to welding current was plotted to identify the distribution of quality welding parameter, the limiting range of welding parameter was set to guide the process of selection. The trend-line formulae and the limits of welding parameter were incorporated into a calculator format so that the output could be displayed digitally.

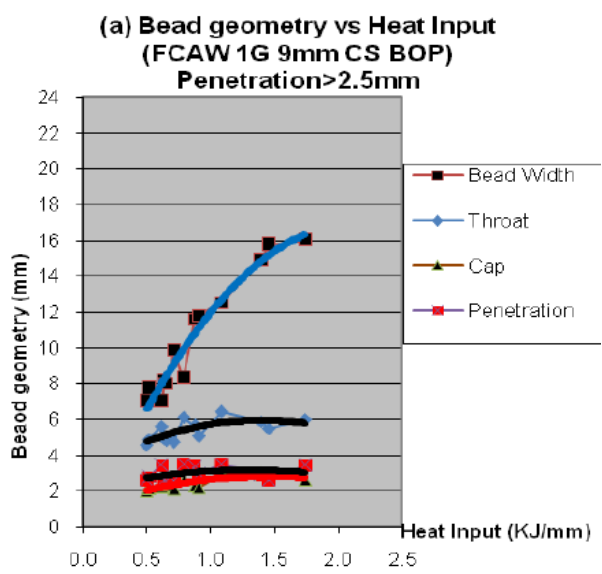

(b) Bead geometry vs Heat Input (FCAW 1G 9mm CS BOP) Penetration $1.5>2.5 \mathrm{~mm}$

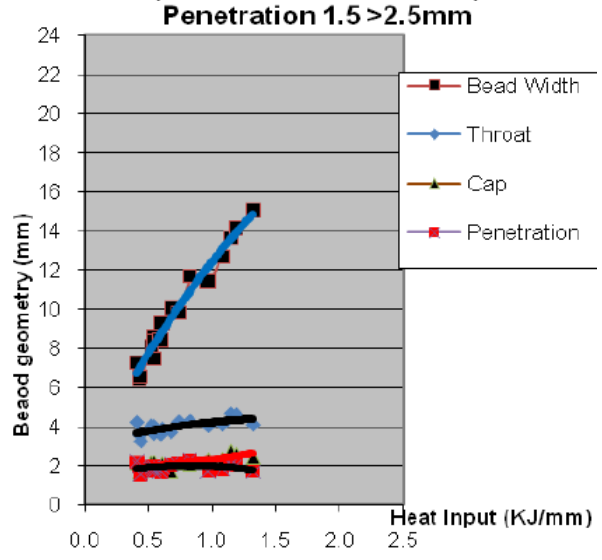

(c) Bead geometry vs Heat Input (FCAW 1G 9mm CS BOP)
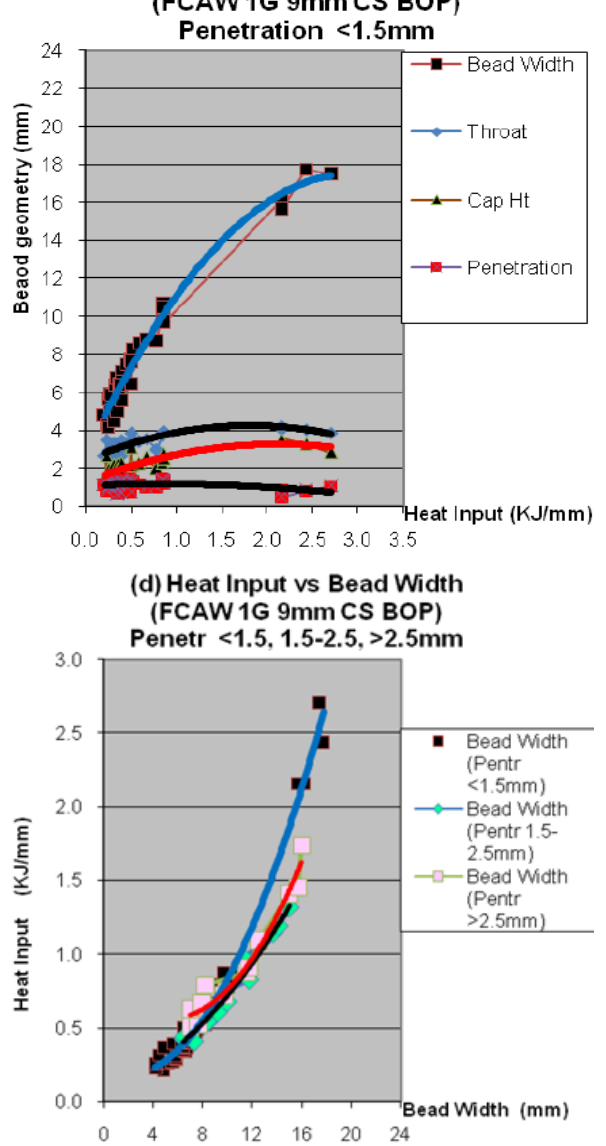

Fig. 1. The correlation of weld bead geometry and heat input. 


\section{RESUlt AND DisCUSSION}

A total of 160 samples each welded with difference welding parameter, only 80 samples were accepted for analysis. Macro samples were prepared and photographed with a ruler. The bead geometry were measured from the macro samples, tabulated with respect to heat input, in order to investigate the correlation between weld bead geometry and heat input.

Four charts in Fig. 1 show the trend-line of correlation between weld bead geometry and heat input for three levels of bead penetration. The formula of each trend-line was used to predict the bead geometry.

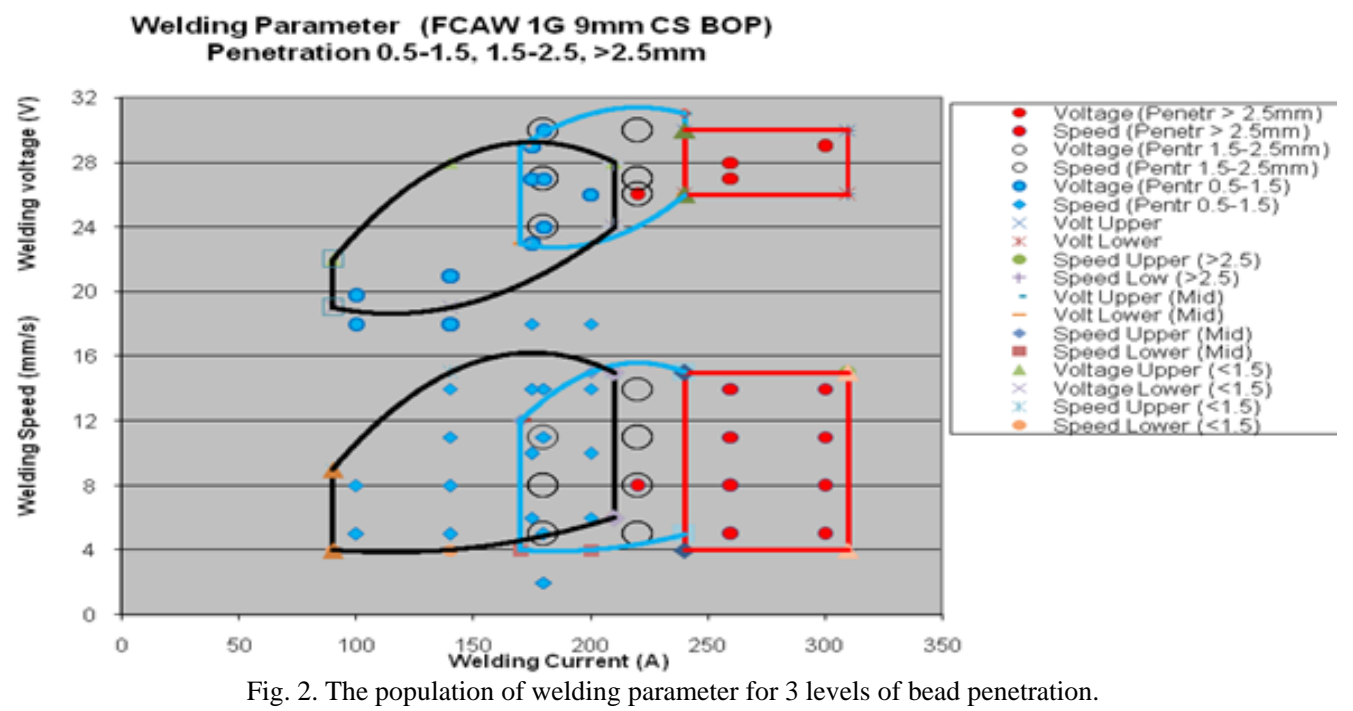

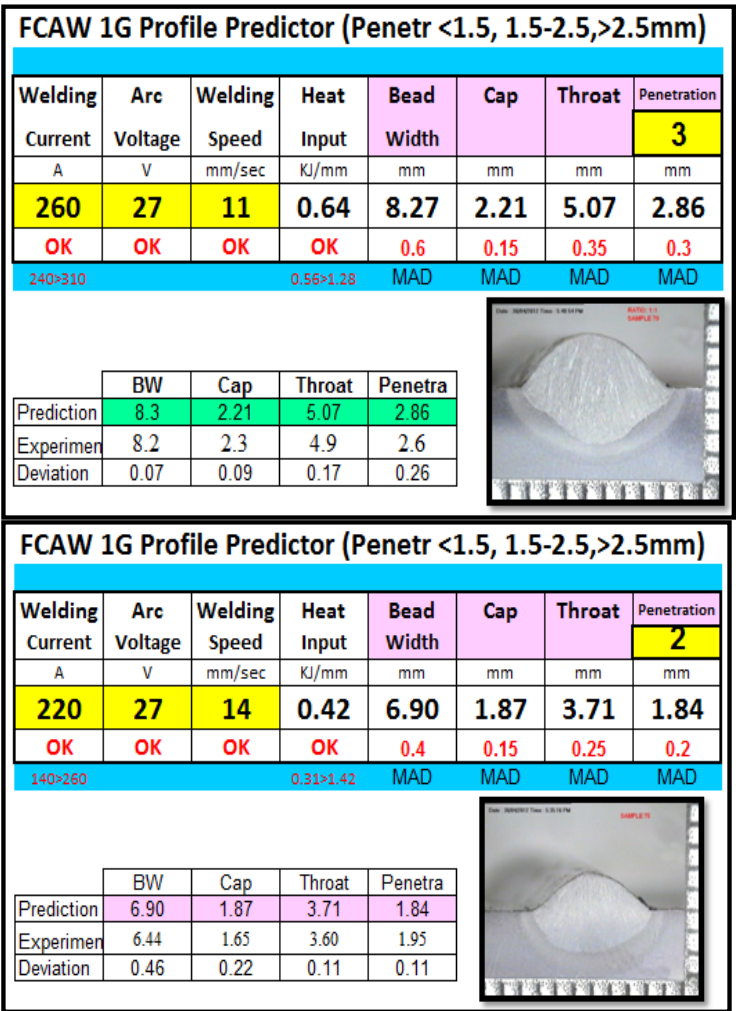

Fig. 3. The prediction calculator, the measured deviation and macro-view.

The distribution of welding parameter population for three levels of bead penetration is shown in Fig. 2. If welding parameter is selected within the distribution limits, there is high probability that the weld bead will be of good quality and its geometry can be accurately predicted. To apply the prediction calculator, the intended bead penetration has to registered first, and then the calculator will guide the user to obtain both welding parameter and weld bead profile. The parameter chart should also be consulted in selection of current, voltage and speed.
Fig. 3 shows the predicted welding parameter and bead geometry for two samples. After welded by FCAW process, the weldments were macro-etched and their bead geometries were measured and compared. The deviations or error values in the weld bead profile are less than $0.3 \mathrm{~mm}$, the predicted data matched closely with experimental results.

TABLE I: MEAN AbSOLUTE DEVIATION FOR 80 BEAD-ON-PLATE SAMPLES

\begin{tabular}{|c|c|c|c|c|}
\hline & $\begin{array}{c}\text { Bead } \\
\text { Width } \\
(\mathrm{mm})\end{array}$ & $\begin{array}{c}\text { Cap } \\
\text { height } \\
(\mathrm{mm})\end{array}$ & Throat & Penetration \\
$(\mathrm{mm})$ & $(\mathrm{mm})$ \\
\hline $\begin{array}{c}\text { MAD } \\
(\text { Penetr }>2.5 \mathrm{~mm})\end{array}$ & 0.60 & 0.15 & 0.35 & 0.33 \\
\hline $\begin{array}{c}\text { MAD } \\
(\text { Penetr1.5-2.5mm) }\end{array}$ & 0.41 & 0.14 & 0.24 & 0.16 \\
\hline $\begin{array}{c}\text { MAD } \\
(\text { Penetr<1.5mm) }\end{array}$ & 0.47 & 0.22 & 0.17 & 0.18 \\
\hline
\end{tabular}

\section{CONCLUSION}

Based on the 80 welded samples, $95 \%$ of deviation of predicted bead geometry is less than $1 \mathrm{~mm}$, only 4 samples has deviation more than $1 \mathrm{~mm}$. Table I shows that the highest MAD is less than $0.6 \mathrm{~mm}$. With this prediction tool, quality welding can be obtained in a single try, and its bead geometry and welding parameters can be predicted accurately before welding.

\section{REFERENCES}

[1] V. V. Kumar, "Effect of FCAW process parameter on weld bead geometry in stainless steel cladding,” JMMCE, vol. 10, no.9, pp. 827-842, 2011.

[2] A. Aloraier et al., "Role of welding parameters using the flux cored arc welding process of low alloy steels on bead geometry and mechanical properties," Journal of materials engineering and performance, vol. 21, no. 4, pp. 540-547, 2012. 
[3] D. Katherasan et al., "Flux cored arc welding parameter optimization using particle swarm optimization algorithm," Procedia Engineering, no. 38, pp. 3913-3926, 2012.

[4] J. Huissoon et al., "Multi-variable control of robotic gas metal arc welding," Journal of Materials Processing Technology, vol. 43, no. 1, pp. 1-12, 1994

[5] W. P. U. A. F. Replacing, "Weld quality prediction of submerged arc welding process using a function replacing hybrid system,” Advances in Production Engineering \& Management, p. 5, 2010.

[6] W. Wang, S. Liu, and J. Jones, "Flux cored arc welding: Arc signals, processing and metal transfer characterization," Welding Journal-Including Welding Research Supplement, vol. 74, no. 11, p. 369, 1995.

[7] S. Kou, Welding Metallurgy, Cambridge Univ Press, 1987.

[8] K. Faes et al., "Parameter optimisation for automatic pipeline girth welding using a new friction welding method,” Materials \& Design, vol. 30, no. 3, pp. 581-589, 2009.

[9] I. Kim et al., "A study on relationship between process variables and bead penetration for robotic $\mathrm{CO}<\mathrm{sub}>2</$ sub $>$ arc welding," Journal of Materials Processing Technology, vo1. 36, no. 1, pp. 139-145, 2003.

[10] K. Pal and S. K. Pal, "Effect of pulse parameter on weld quality in pulsed gas metal arc welding: A review," Journal of Materials Engineering and Performance, vol. 2, no. 6, pp. 918-931, 2010.

[11] H. H. Na, I. S. Kim, B. Y. Kang, and J. Y. Shim, "A experiment study for welding optimization of fillet welded structure," J. Achiev. Mater. Manuf. Eng., vol. 45, no. 2, pp. 178-187, 2011.

[12] P. Mukhopadhyay, S. Chattopadhyaya, S. Bhatia, N. K. Singh, and A. K. Mukhopadhyay, "Prediction of weld parameters in gas metal arc welding process using curve arc fitting techniques and graphical methods,” Adv. Mater. Res., vol. 652-654, pp. 2352-2356, 2013.

[13] D. Katherasan, J. V. Elias, P. Sathiya, and A. N. Haq, "Simulation and parameter optimization of flux cored arc welding using artificial neural network and particle swarm optimization algorithm," J. Intell. Manuf. no. 2007, pp. 0-9, 2012.

[14] G. Tham, M. Y. Yaakub, S. K. Abas, Y. H. P. Manurung, and B. A. Jalil, "Predicting the GMAW 3F T-fillet geometry and its welding parameter," Procedia Eng., vol. 41, pp. 1794-1799, 2012.

[15] S. H. A. Hamidin, G. Tham, Y. H. P. Manurung, and S. K. Abas, "Predicting bead geometry of 2F-fillet joint welded by small wire SAW,” Adv. Mater. Res., vol. 576, pp. 185-188, 2012.

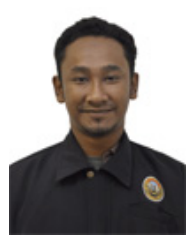

MohdFaizal Bin Abdul Razak was born on February 20, 1988 in Kangar, Perlis. He graduated on degree in mechanical engineering (Hons) from Universiti Teknology Mara (UiTM) Shah Alam. Currently he is pursuing master in mechanical engineering from Universiti Teknology Mara (UiTM) Shah Alam.

He worked as a technical assistance in production, planning and engineering at Azman Hamzah Plastics, Shah Alam. He is working as an assistance lecturer at Universiti of Kuala Lumpur Marine Institute of Marine Engineering Technology (UniKL MIMET) and in authority teaching welding technology subjects for diploma level.

Recently he has certified Welding Inspector 3.0. He attended 2015
International Conference on Mechatronics and Robotics Engineering (ICMRE 2015).

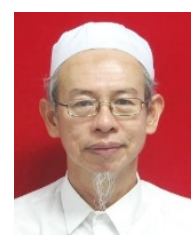

Abdul GhalibTham was born in 1951 in Malaysia. He got his master of engineering from UTM, Skudai, in 1992, welding process. He worked as a project engineer, design engineer, welding inspector and welding consultant in Jurong Engineering Ltd. and SIRIM Bhd.

His current job is a lecturer in UiTM, Shah Alam, undertaking research in prediction of welding parameters and weld bead geometry in SAW, GMAW and FCAW in all-position butt and fillet joints.

He had developed several tools for accurate prediction of welding parameters and bead geometries for robotic welding application.

He is a member of Institute of Materials, Malaysia

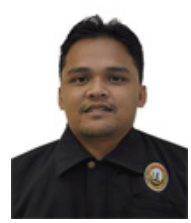

Mohd Amin Hakim B Ramli was born in Subang Jaya on April 1, 1986. He obtained master in offshore floating system from the University of Strathclyde, Glasgow with distinction in September 2011.

He is currently working as a lecturer at Universiti of Kuala Lumpur Marine Institute of Marine Engineering Technology (UniKL MIMET) and responsible in carrying out teaching various subjects to bachelor degree and diploma students. His previous research interest was in underwater vehicle. He attended the 6th Asia Pacific Workshop on Marine Hydrodynamics (AP HYRO) Preliminary Design of AUV (Autonomous Underwater Vehicle) with Higher Resolution Underwater Camera for Marine Exploration in 2012 and the 8th International Conference on Marine Technology 2012 (MARTEC) Chassis Design of an Unmanned Underwater Glider (UUG-MIMET1). Currently, he is focusing on research of materials and welding.

He has recently become a member of Malaysian Society for Engineering and Technology (MySET). He received a bronze medal under renewable energy from ITEX 2014 (International Invention, Innovation \& Technology Exhibition). The research conducted was on the development of solar boat. 